\title{
O Balanced Scorecard e a Gestão Ambiental: Um Estudo no Sector Público e Privado Português
}

\begin{abstract}
Patricia Rodrigues Quesado Doutorado em Ciências Econômicas e Empresariais pela Universidade de Santiago de Compostela Professora da Escola Superior de Gestão do Instituto Politécnico do Cávado e do Ave IPCA

Barcelos. Portugal. CEP: 4750-810 E-mail:pquesado@ipca.pt

Lúcia Lima Rodrigues Doutorado em Ciências Empresariais pela Universidade do Minho Professora da Escola de Economia e Gestão Universidade do Minho Campus de Gualtar. Braga. CEP: 4710-057

E-mail:Irodrigues@eeg.uminho.pt

Beatriz Aibar Guzmán Doutorado em Ciências Econômicas e Empresariais pela Universidade de Santiago de Compostela Professora Titular na Universidade de Santiago de Compostela Santiago de Compostela. Espanha. CEP: 15782 E-mail: beatriz.aibar@usc.es
\end{abstract}

\section{RESUMO}

Os aspectos sociais e ambientais são reconhecidos cada vez mais como estratégicos na organização, na medida que constituem novas oportunidades de criação de valor mediante o desenvolvimento de vantagens competitivas capazes de diferenciar as empresas dos seus concorrentes actuais e potenciais. A adopção e o desenvolvimento de novas tecnologias, estratégias e instrumentos de gestão das questões sociais e ambientais parece ser hoje uma matéria indiscutível. No entanto, são várias as dificuldades encontradas na quantificação económica e financeira das políticas de desenvolvimento sustentável, levando ao desenvolvimento ou adaptação de ferramentas de gestão, como é o caso do Balanced Scorecard (BSC). Assim, no sentido de averiguarmos se as organizações públicas e privadas portuguesas incluem nos seus scorecards indicadores sociais e ambientais e se existe relação entre a utilização do BSC e os sistemas de certificação ambiental, enviamos um questionário a 591 organizações públicas e 549 organizações privadas portuguesas, com uma taxa de resposta de $31,3 \%$. Os resultados obtidos permitem concluir que a maioria dos inquiridos inclui indicadores sociais e ambientais nos seus scorecards e que as empresas certificadas em termos ambientais utilizam mais o BSC do que as não certificadas. 
O Balanced Scorecard e a Gestão Ambiental: Um Estudo no Sector Público e Privado Português

Patricia Rodrigues Quesado, Lúcia Lima Rodrigues, Beatriz Aibar Guzmán

Palavras-chave: Balanced Scorecard. Contabilidade de Gestão. Gestão Ambiental.

\title{
The Balanced Scorecard and Environmental Management: A Study in the Public and Private Portuguese Sector
}

\begin{abstract}
The social and environmental aspects are increasingly recognized as strategic in the organization, as they provide new opportunities for value creation through the development of competitive advantages that can differentiate companies from their current and potential competitors. The adoption and development of new technologies, strategies and tools for managing social and environmental issues is, nowadays, a matter beyond dispute. However, there are several difficulties in quantifying economically and financially the policies for sustainable development, leading to the development or adaptation of management tools, such as the Balanced Scorecard (BSC). Thus, in order to find out if the Portuguese public and private organizations include social and environmental indicators in their scorecards, and whether there is a relationship between the use of the BSC and environmental certification systems, we sent a questionnaire to 591 public and 549 private organizations in Portugal, with a response rate of $31.3 \%$. The findings suggest that most of the respondents include social and environmental indicators in their scorecards and that environmentally certified companies use BSC more than non-certified.
\end{abstract}

Keywords: Balanced Scorecard. Management Accounting. Environmental Management.

\section{INTRODUÇÃO}

Nos últimos anos verifica-se uma crescente preocupação por parte das organizações com os impactos ambientais e sociais sobre as actividades e resultados das mesmas, e consequente divulgação (LÄNSILUOTO; JÄRVENPÄÄ, 2010; LAMEDA MONTERO; GIMENO ZUERA, 2009; LÄNSILUOTO; JÄRVENPÄÄ, 2008, 2007; DIASSARDINHA et al.., 2007; YONGVANICH; GUTHRIE, 2006; SCHALTEGGER; WAGNER, 2006; DIAS-SARDINHA; REIJNDERS, 2005; TING, 2005; MÖLLER; SCHALTEGGER, 2005; DIAS-SARDINHA et al., 2002; DIAS-SARDINHA; REIJNDERS, 2001). Não obstante, se as empresas pretendem sobreviver num mercado globalizado e competitivo não podem apenas preocupar-se com o controlo dos impactos 
ambientais, mas também com a avaliação do desempenho ambiental, devendo incluir na listagem de objectivos estratégicos, iniciativas ambientais e de bem-estar da comunidade e empregados.

O estudo empírico que realizamos teve por objectivo principal averiguar se as organizações públicas e privadas portuguesas incluem nos seus scorecards indicadores sociais e ambientais e se existe relação entre a utilização do BSC e a certificação ambiental das organizações portuguesas pertencentes, quer ao sector privado quer ao sector público. Paralelamente, procuramos proporcionar algumas ideias acerca da importância e necessidade de integração da gestão ambiental no BSC.

O presente artigo encontra-se organizado da seguinte forma: inicialmente expõese a relevância do BSC na gestão ambiental. Posteriormente, descrevem-se alguns aspectos teóricos relativos à problemática de inclusão dos indicadores sociais e ambientais no BSC, analisando as distintas possibilidades de inclusão. Com esta base, apresentamos e analisamos os modelos de BSC orientados ao desenvolvimento sustentável. Finalmente, apresentamos a relação entre o BSC e a Global Reporting Initiative (GRI), assim como a inter-relação entre o BSC e a gestão ambiental no contexto português com base nos resultados obtidos de um estudo empírico realizado em organizações públicas e privadas portuguesas.

\section{REVISÃO DA LITERATURA}

\subsection{A importância do BSC para a gestão ambiental}

O interesse na inclusão de aspectos da gestão ambiental no BSC é crescente dada a relevância dos aspectos estratégicos e da integração de indicadores não financeiros para a organização. Apesar de Kaplan e Norton (2008; 2007a; 2007b; 2006; 2004; 2001; 2000; 1996; 1992) não abordarem explicitamente a variável ambiental, a utilização do BSC como uma ferramenta de gestão das temáticas social e ambiental foi sugerida por distintos autores (CHALMETA; PALOMERO, 2011; LÄNSILUOTO; JÄRVENPÄÄ, 2010; HSU; LIU, 2010; GATES; GERMAISN, 2010; LÉON et al., 2010; 
HUBBARD, 2009; LAMEDA MONTERO; GIMENO ZUERA, 2009; LÄNSILUOTO; JÄRVENPÄÄ, 2008, 2007; DIAS-SARDINHA et al., 2007; CLAVER-CORTÉS et al., 2007; GILLI, 2007; LÓPEZ; LLENA, 2006; SCHALTEGGER; WAGNER, 2006; LÓPEZ, 2006; MÖLLER; SCHALTEGGER, 2005; DIAS-SARDINHA; REIJNDERS, 2005; TING, 2005; GIMENO et al., 2005; ZINGALES; HOCKERTS, 2003; MONTEIRO et al., 2003; BEJA, 2003; ZINGALES et al., 2002A, 2002B; FIGGE et al., 2002; BIEKER, 2002; DIAS-SARDINHA et al., 2002; CAMPOS; SELIG, 2002; DIAS-SARDINHA; REIJNDERS, 2001; EPSTEIN; WISNER, 2001; CAMPOS, 2001; BIEKER; GMINDER, 2001; TORRES, 2001; BANEGAS et al., 2000; JOHNSON, 1998) e associações, derivado dos benefícios que tal variável poderá reflectir no desempenho financeiro da empresa. No entanto, os autores são unânimes em considerar que a implementação e utilização do BSC como ferramenta de planeamento estratégico em que se integram políticas de desenvolvimento sustentável não é tarefa fácil, requerendo tempo, técnica e persistência, devendo constituir uma base coerente e integrada na comunicação externa e interna.

Johnson (1998) refere que o BSC é o instrumento adequado na identificação e selecção equilibrada de indicadores ambientais estrategicamente relevantes, capazes de conduzir a organização na realização de metas e objectivos ambientais. $O$ autor considera que o desempenho estratégico é função do desempenho ambiental. Assim, o BSC é uma ferramenta útil para justificar à gestão de topo, a necessidade de realizar investimentos em estratégias ambientais e que se deve associar um sistema de incentivos capaz de motivar o pessoal na realização dos objectivos ambientais estratégicos.

Para Torres (2001), o BSC ambiental é uma ferramenta de medição do desempenho empresarial que permite avaliar e controlar a eficiência e efectividade na aplicação dos recursos financeiros destinados para a execução do plano estratégico ambiental, assim como fazer um seguimento continuo, passo a passo da evolução dos resultados no desenvolvimento e implementação de uma estratégia ambiental. De acordo com o autor, o importante é que o BSC proporcione às diferentes organizações 
informação relacionada com a sua actividade e os efeitos e impactos ambientais que gera o desenvolvimento do seu objecto social, de modo a promover e gerar consciência da sua influência no meio ambiente. Por conseguinte, o BSC ambiental deverá contribuir para estabelecer elementos de medição qualitativos e quantitativos, para estabelecer indicadores de desempenho ambiental e para identificar os responsáveis pelos diferentes processos de gestão ambiental.

Epstein e Wisner (2001) consideram que a abordagem do BSC é de grande utilidade para as organizações que pretendam uma gestão proactiva dos aspectos sociais e ambientais, ajudando a identificar as medidas sociais e ambientais chave do desempenho e a sua vinculação com os objectivos estratégicos, a comunicar a importância de estas iniciativas, a medir o impacto de estes programas no desempenho organizacional e a compreender trade-offs entre os efeitos sociais, económicos e ambientais de investimentos específicos.

Por outra parte, Banegas et al. (2000) analisaram a utilidade da aplicação do BSC ao âmbito da gestão social, argumentando que será necessário que o sistema de controlo de gestão de uma organização inclua variáveis sociais, tanto em relação aos recursos humanos como ao meio ambiente, uma vez que as organizações necessitam assumir uma responsabilidade social, superando a obrigação mínima de produzir bens e serviços para a sociedade. Para os referidos autores, a inclusão de variáveis relativas às diferentes políticas de pessoal, assim como às políticas ambientais, vai permitir à organização alcançar uma dimensão dinâmica e prospectiva do controlo sócioambiental, na medida que vai permitir, a cada nível de responsabilidade, dispor de maneira rápida e eficiente de um sistema de recolha, tratamento e interpretação da informação "eco-social" e, em consequência, proceder ao controlo da gestão realizada.

Segundo Beja (2003), a utilização de mapas estratégicos nas matérias ambientais e de sustentabilidade facilitará o processo de tomada de decisão por parte da gestão, evidenciando a inter-relação de objectivos consequentes do negócio base com opções estratégicas resultantes de uma política de desenvolvimento sustentável. Assim, na visão do citado autor podemos atender aos seguintes objectivos: 
> Satisfação dos clientes (através do incremento de produtos ecológicos, conduzindo à aquisição de novos clientes e ao aumento das vendas);

> Melhoria da qualidade dos produtos (através da redução dos desperdícios de produção, com efeitos na redução dos custos e na viabilidade de certificação ambiental que proporcione a satisfação dos clientes);

> Incremento na satisfação da comunidade local (através de um projecto para educação ambiental nas escolas, com impacto positivo na retenção dos fornecedores locais (...), e na motivação dos empregados);

> Lançamento de um projecto de pro-actividade ambiental com efeitos na motivação dos empregados.

Face ao exposto, verificamos que as variáveis sociais, entre elas, as actuações ambientais devem estar presentes na visão das organizações, assim como a preocupação de como os objectivos e valores ambientais se inter-relacionam e são coordenados dentro da organização e como afectam os processos de tomada de decisão. Neste sentido, seguindo a opinião de López (2006, p.3), o BSC cobra especial relevância na gestão e controlo da variável ambiental como área chave da estratégia,

uma vez que permite melhorar a implementação e o seguimento da estratégia mediante a definição de uns objectivos estratégicos, a identificação das variáveis chave de que depende o êxito, o estabelecimento de indicadores sobre a consecução dos objectivos propostos, e a construção de relações causa-efeito entre os objectivos definidos e os indicadores destinados a medir 0 seu grau de consecução (...).

A referida autora assinala que se bem que por motivos estratégicos o BSC não deverá ser publicado na sua totalidade e os indicadores ambientais se utilizem internamente para a gestão, seria aconselhável que as organizações dessem a conhecer à sociedade ${ }^{1}$ os aspectos relacionados com a sua actuação ambiental através da divulgação dos indicadores relativos a estes aspectos que se encontram

\footnotetext{
${ }^{1}$ Mediante relatórios de gestão ou relatórios específicos de sustentabilidade.
} 
incorporados no BSC, o que implicará a existência de regulação ou guias que normalizem os indicadores objecto de divulgação.

\subsection{Inclusão dos indicadores sociais e ambientais no BSC}

A principal questão levantada em relação ao BSC na gestão ambiental é precisamente a inclusão dos indicadores ambientais e sociais no mesmo. No que concerne a esta matéria podemos encontrar posições distintas entre os autores:

$>$ Distribuição dos indicadores do desempenho ambiental e social, em combinação com os restantes indicadores de gestão, pelas quatro perspectivas tradicionais do BSC (LÓPEZ, 2006; MONTEIRO et al., 2003; FIGGE et al., 2002; EPSTEIN; WISNER, 2001; TORRES, 2001; OLVE et al., 1999; JOHNSON, 1998).

Os autores referidos consideram que em todas as perspectivas propostas por Kaplan e Norton (1996) a variável ambiental apresenta um papel relevante, devendo incorporar-se os indicadores precisos para a sua gestão, uma vez que a gestão sustentável deve implicar todos os níveis hierárquicos e estar presente em todos os processos económicos de uma organização.

Olve et al. (1999) e Johnson (1998) sugerem a extensão das quatro perspectivas originais a outros stakeholders como o governo e organizações ambientais não governamentais. Monteiro et al. (2003) e Torres (2001) defendem esta possibilidade, uma vez que além de preservar a estrutura compacta do modelo de Kaplan e Norton (2001; 2000; 1996), possibilita que as questões ambientais não sejam vistas como uma formulação independente da organização, fazendo parte do espírito que está associado às actividades executadas. Neste sentido, o facto de considerar-se as variáveis ambientais como parte integrante das quatro perspectivas, não significa que essas variáveis constituem uma questão adicional.

Assim, na perspectiva de aprendizagem e crescimento a ênfase seria colocada na preparação dos empregados orientada para as questões ambientais; na perspectiva interna o centro de atenção seria o desenvolvimento de serviços "ambientalmente eficientes"; na perspectiva de clientes seria importante considerar as oportunidades 
para produtos/serviços "verdes"; e na perspectiva financeira, os impactos de uma actuação livre de riscos ambientais. Os autores consideram, ainda, que não é apenas a gestão ambiental que se beneficia desta integração. Na verdade, a incorporação do tratamento dos aspectos ambientais estratégicos torna mais completo o BSC.

Radcliffe (apud ZINGALES et al., 2002a) refere a importância do BSC para reduzir a distância entre as funções financeira e ambiental, no entanto, considera que se deverão efectuar algumas modificações no BSC original para integrar conceitos e práticas de sustentabilidade no sistema de gestão, em concreto, a criação de uma visão compartida sobre a necessidade de integração da sustentabilidade na organização. Neste sentido, a perspectiva financeira deverá incluir oportunidades de redução de riscos e de melhoria da posição competitiva, redução de custos e incremento da produtividade através de estratégias ambientais. Por outra parte, a perspectiva de clientes deverá ser alargada para incluir agências governamentais, organizações não governamentais, analistas financeiros (stakeholders externos) e empregados e colegas em outras funções (stakeholders internos). No que respeita à perspectiva de processos internos deverá incluir a revisão de programas de gestão ambiental existentes e da sua interacção com a cadeia de valor. Finalmente, na perspectiva de aprendizagem e crescimento inclui-se a habilidade para integrar a sustentabilidade e conhecer os objectivos das restantes perspectivas.

López (2006) argumenta que a determinação e a identificação dos aspectos relevantes da variável ambiental associados a cada dimensão do BSC dependerá do tipo de organização e dos objectivos em matéria de meio ambiente que se persigam o que virá condicionado pela atitude da empresa perante estas questões (grau de compromisso ambiental, tipo de actividade que realize, tipo e causa dos impactos ambientais que origina, factores externos aos que se encontra sujeita, em concreto, grupos de pressão, legislação, concorrência, etc., possibilidade de obtenção de informação existente na empresa, entre outros aspectos). Para a citada autora, a incorporação da variável ambiental nas perspectivas clássicas do BSC requer a prévia identificação das áreas chave ou categorias a gerir, definindo-se os indicadores 
correspondentes a cada perspectiva em função dos objectivos ambientais que se pretendem controlar, sugerindo ainda a modificação da denominação das perspectivas tradicionais propostas por Kaplan e Norton (1996). Assim, a perspectiva de aprendizagem e crescimento deverá designar-se perspectiva de inovação, aprendizagem e recursos humanos, e na perspectiva de clientes devem incluir-se outros agentes do ambiente organizacional com interesse na actuação ambiental da empresa (perspectiva de clientes e outros agentes sociais).

> Criação de uma quinta perspectiva para a gestão ambiental, geralmente denominada de perspectiva ambiental e de responsabilidade social ${ }^{2}$ (MORO; FERNÁNDEZ, 2003; BASTIDAS; RIPOLL, 2003; FIGGE et al., 2002; CAMPOS; SELIG, 2002; CAMPOS, 2001; KAPLAN; NORTON, 2000; OLVE et al., 1999).

Torres (2001) considera que uma perspectiva exclusiva para o meio ambiente pode ser útil em organizações que estão a passar por uma profunda mudança cultural. Neste sentido, Epstein e Wisner (2001) comprovaram que as organizações que adicionaram uma quinta perspectiva ao BSC original consideraram a responsabilidade social e ambiental como um imperativo estratégico na criação de vantagens competitivas (e não como uma forma de melhoria da eficiência operativa), para centrar os directores e empregados nestes tópicos e para justificar investimentos.

Para Moro e Fernández (2003, p. 183), a inclusão desta nova perspectiva "poderá ajudar enormemente a fixação dos objectivos ambientais, o controlo do seu grau de consecução e a medição e análise das consequências que o seu cumprimento ou incumprimento tem sobre as metas globais da organização".

Bieker e Gminder (2001) defendem a inclusão de uma quinta perspectiva (denominada perspectiva da sociedade ${ }^{3}$ ) em aquelas organizações muito expostas às questões sustentáveis. Não obstante, Rocha et al. (2001) não concordam com esta

\footnotetext{
${ }^{2}$ Kaplan e Norton (2000), ao considerarem que as perspectivas do BSC, apesar de se revelarem adequadas em diversas empresas e sectores de mercado, não devem ser vistas como uma "camisa-de-forças", admitem a hipótese de adicionar outras perspectivas. Os autores relatam o caso de uma empresa que por trabalhar com produtos químicos adicionou ao seu scorecard a perspectiva ambiental, na medida em que o desempenho ambiental era considerado um dos factores críticos para o êxito da estratégia empresarial, mostrando à comunidade a preocupação da empresa com as questões ambientais.

${ }^{3}$ Para integrar outros stakeholders como a população, Estado, autoridades públicas e organizações não governamentais.
} 
opção na medida que consideram que apenas uma perspectiva complementar seria insuficiente porque não especifica a adopção de uma estratégia capaz de contemplar questões ambientais de uma forma mais específica, pelo contrário, transmite um carácter macro da visão estratégica a ser adoptada pela organização, isto é, a temática ambiental é apenas mais uma variável a ser medida. Os referidos autores argumentam, ainda, que a utilização de apenas uma única perspectiva para as matérias ambientais incorporaria pelo menos 25 novos indicadores, demonstrando um desequilíbrio comparativamente às restantes perspectivas. Assim, efectuaram um estudo no qual propõem um modelo de BSC para a gestão ambiental, contemplando seis perspectivas para uma eficiente gestão ambiental (quadro 1).

\begin{tabular}{|c|c|}
\hline Perspectivas do BSC & Comentário \\
\hline Jurídica & $\begin{array}{c}\text { As actividades empresariais devem estar em conformidade com a } \\
\text { legislação ambiental. Assim, esta perspectiva centra-se no cumprimento } \\
\text { das determinações instituídas pela legislação ambiental, cumprimento } \\
\text { esse que estará facilitado se existir uma sensibilização de todos para as } \\
\text { questões ambientais. }\end{array}$ \\
\hline Económica/Financeira & $\begin{array}{c}\text { Incremento do volume de vendas, aumento da quota de mercado, } \\
\text { conquista e fidelização de clientes, como reflexo da relação positiva da } \\
\text { organização com o meio ambiente. }\end{array}$ \\
\hline $\begin{array}{l}\text { Engenharia de } \\
\text { Produção }\end{array}$ & $\begin{array}{l}\text { O processo de engenharia não deve interferir no meio ambiente. Desta } \\
\text { forma, todos devem ter uma visão ambiental no desenvolvimento das suas } \\
\text { actividades e na utilização de equipamentos, máquinas e processos } \\
\text { organizacionais. }\end{array}$ \\
\hline Imagem/Marketing & $\begin{array}{c}\text { O objectivo desta perspectiva prende-se com a transmissão da relação da } \\
\text { organização com o meio ambiente, ou seja, com o reconhecimento, por } \\
\text { parte dos empregados, colaboradores e sociedade, da conduta ambiental } \\
\text { sustentável mantida pela empresa. }\end{array}$ \\
\hline Recursos Humanos & $\begin{array}{l}\text { Desenvolvimento da educação ambiental para consciência e } \\
\text { sensibilização dos empregados e colectividade da relação da organização } \\
\text { com o meio ambiente e dos seus impactos nos seus valores e crenças. }\end{array}$ \\
\hline
\end{tabular}

Quadro 1: Perspectivas de um modelo de BSC para a gestão ambiental Fonte: Elaboração própria, a partir de Rocha et al., 2001. 
> Uma abordagem parcial através da inclusão dos indicadores ambientais em algumas dimensões do BSC.

Länsiluoto e Järvenpää (2007) apresentam um estudo de caso de uma empresa finlandesa que incluiu os indicadores ambientais apenas na perspectiva de processos internos uma vez que o objectivo principal da organização não é apenas a melhoria da gestão ambiental. Por outra parte, Johnson (1998) incorpora os componentes de âmbito social ou ambiental na chamada perspectiva de clientes e stakeholders externos. Para López e Llena (2006) esta opção tem o inconveniente de centrar a Responsabilidade Social Corporativa (RSC) de forma primordial na perspectiva externa do cliente, o que pode levar as empresas a fazer as coisas não por convicção mas por imagem. Além disso, referem que a gestão ambiental tem uma natureza de carácter marcadamente intrínseco.

$>$ Tratamento do departamento de gestão ambiental como uma SSU ${ }^{4}$, com a construção de um BSC específico. Assim, caso a empresa possua um departamento de gestão ambiental ou de sustentabilidade, deve ser desenvolvido um BSC próprio para essa Unidade Estratégica de Negócios (UEN) (HUBBARD, 2009; FIGGE et al., 2002; EPSTEIN; WISNER, 2001; AECA, 1996).

Figge et al. (2002) defendem que a selecção de estas alternativas irá depender dos aspectos inerentes às questões ambientais. Ou seja, se estamos frente a aspectos internalizados no sistema de mercado em que os aspectos ambientais e sociais são estratégicos ou drivers de desempenho numa ou mais perspectivas, então devemos optar pela primeira alternativa, isto é, os aspectos sociais e ambientais são parte integrante do scorecard convencional. No entanto, se estamos na presença de externalidades $^{5}$, estas devem ser incluídas numa quinta perspectiva e tratadas separadamente para garantir uma adequada visibilidade. Para os citados autores existem duas condições para a inclusão de uma perspectiva adicional no scorecard: que os aspectos sociais e ambientais sejam estrategicamente relevantes e que não

\footnotetext{
${ }^{4}$ Shared Service Units.

${ }^{5}$ Muitos aspectos sociais e ambientais ainda não estão integrados no mecanismo de coordenação do mercado.
} 
seja possível uma adequada incorporação dos mesmos nas perspectivas convencionais do BSC.

Monteiro et al. (2003) colocaram algumas reticências a este respeito sobretudo devido à dificuldade que pode existir na determinação do nível de internalização dos aspectos ambientais.

Segundo Maside e Aibar (1999), a selecção de uma ou outra alternativa depende do peso das variáveis ambientais no conjunto de elementos de decisão e da actuação estratégica da organização, que por sua vez dependem do impacto da actividade empresarial no ambiente físico e natural, das pressões exercidas sobre a empresa para uma actuação mais cuidadosa e da posição estratégica seleccionada (influenciada pela cultura organizacional e pela ética e valores ambientais da empresa). Para os citados autores, a primeira alternativa é seleccionada por aquelas empresas com pouco impacto ambiental, que deverão desenvolver indicadores financeiros e não financeiros para avaliar o desempenho ambiental. Por sua vez, a segunda alternativa deverá ser seleccionada por aquelas empresas que exercem um importante impacto sobre o meio ambiente, de forma a destacar a dimensão ambiental da empresa, o que implica o desenvolvimento de um subsistema de controlo de gestão centrado nos aspectos ambientais.

Os citados autores concluem que a inclusão da perspectiva ambiental no modelo proposto por Kaplan e Norton (1996; 1992) pode ser muito eficaz para dirigir a gestão, apoiando-a na gestão estratégica. Como tal, deve-se traduzir a visão e estratégia organizacional num conjunto de indicadores de avaliação da actuação organizacional que, além de incluírem as variáveis estratégicas funcionais tradicionais, deverão atender a variáveis que têm impactos ambientais.

De acordo com Epstein e Wisner (2001), a inclusão das medidas sociais e ambientais nas perspectivas tradicionais do BSC ou numa quinta perspectiva depende da análise dos drivers de êxito organizacional e da importância das referidas medidas na estratégia e no desempenho da organização. Como referem os autores, cada organização define sustentabilidade de modo distinto e, por conseguinte, os indicadores 
seleccionados e a sua inclusão nas dimensões do BSC depende da estratégia, da missão, da cultura e dos objectivos particulares de cada organização ou unidade de negócio. Para os autores, a inclusão de uma quinta dimensão no scorecard relativa explicitamente aos objectivos sociais e ambientais requer que a gestão de topo reconheça o valor estratégico da nova dimensão, ou seja, que considere a sustentabilidade como um valor chave e um imperativo estratégico da organização para a criação de vantagens competitivas ${ }^{6}$. Além disso, possibilita que os empregados centrem a sua atenção na responsabilidade social e ambiental, incrementando a comunicação organizacional respeito a estas temáticas e à sua inter-relação com as restantes dimensões da organização.

Zingales et al. (2002a) entrevistaram directores do departamento ambiental e a equipa responsável pela implementação do BSC de nove organizações conhecidas pelo seu investimento em estratégias sociais e ambientais. Verificaram que o processo de construção do BSC variou bastante de organização para organização. Para os autores, se o poder do departamento ambiental da organização é baixo, a implementação do BSC não representa uma garantia de que os aspectos ambientais se considerem críticos pelos gestores da organização.

Por outra parte, Bieker e Gminder (2001) consideram que as empresas classificadas como limpas ${ }^{7}$, eficientes ${ }^{8}$ ou inovadoras ${ }^{9}$ devem incluir os indicadores ambientais em apenas uma ou duas perspectivas do BSC tradicional. No entanto, aquelas classificadas como progressivas $^{10}$ devem incluir indicadores de sustentabilidade em todas as dimensões do BSC tradicional ou adicionar uma quinta perspectiva nos seus scorecards.

$\mathrm{Na}$ Figura 1, encontram-se ilustradas as principais inter-relações entre as perspectivas do BSC na gestão ambiental.

\footnotetext{
${ }^{6}$ Imagem, reputação e diferenciação de produtos.

${ }^{7}$ Empresas preocupadas em cumprir com a legislação e em observar cuidadosamente os concorrentes e o mercado.

${ }^{8}$ Procuram a eco-eficiência através da redução dos custos resultantes da ineficiência do processo ambiental.

${ }^{9}$ Procuram a diferenciação para aumentar as vendas e as margens sobre os denominados "produtos verdes".

${ }^{10}$ Procuram uma vantagem competitiva em relação aos concorrentes menos orientados para questões ambientais e sociais.
} 
O Balanced Scorecard e a Gestão Ambiental: Um Estudo no Sector Público e Privado Português

Patricia Rodrigues Quesado, Lúcia Lima Rodrigues, Beatriz Aibar Guzmán

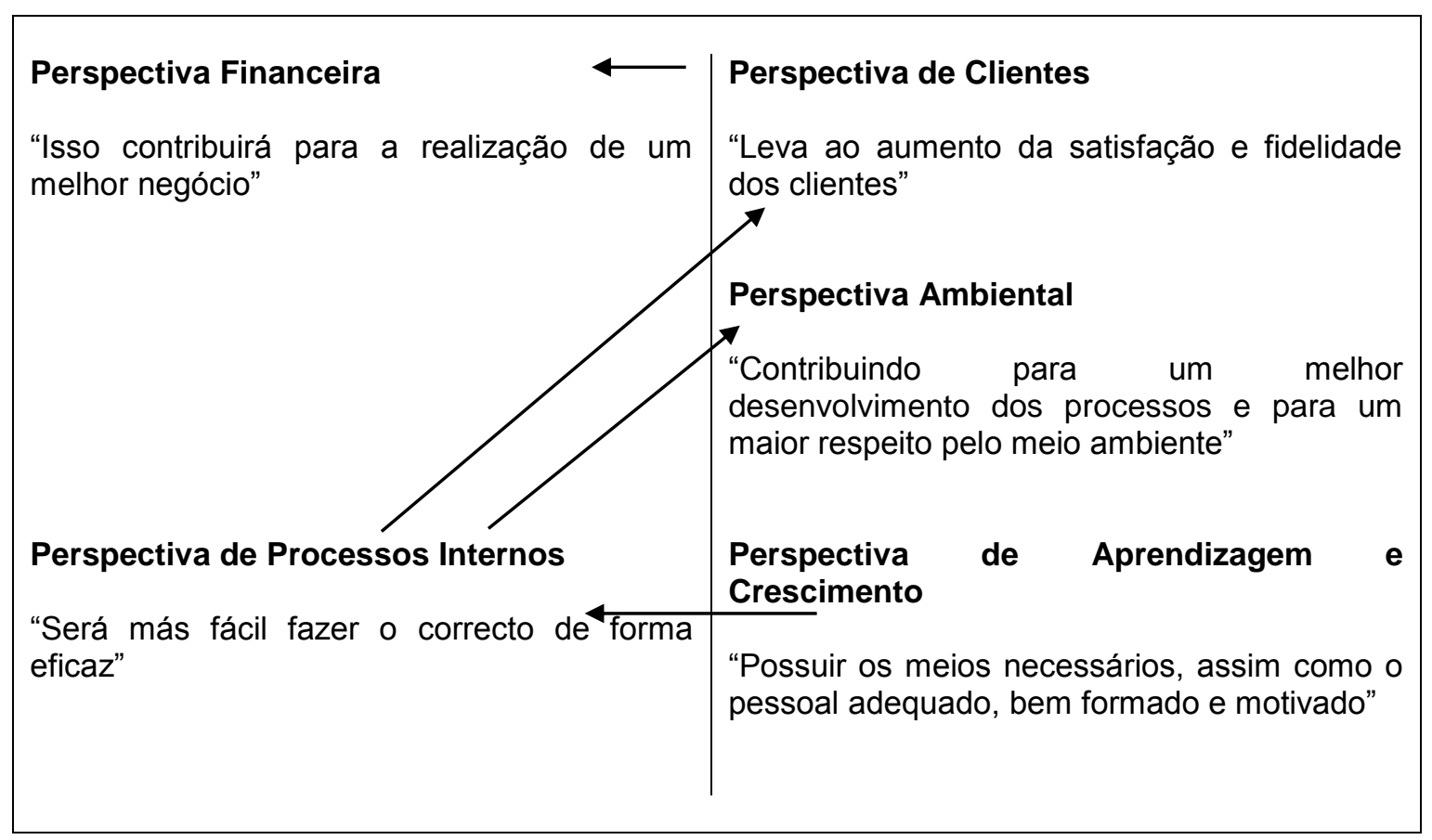

Figura 1: As inter-relações entre as perspectivas do BSC na gestão ambiental Fonte: Olve et al. (apud MORO; FERNÁNDEZ, 2003, p. 183), adaptado.

De seguida apresentamos um quadro resumo (Quadro 2) de empresas que incluíram aspectos ambientais nas perspectivas tradicionais, sugeridas por Kaplan e Norton (1996), ou numa perspectiva adicional criada para o efeito. 
O Balanced Scorecard e a Gestão Ambiental: Um Estudo no Sector Público e Privado Português

Patricia Rodrigues Quesado, Lúcia Lima Rodrigues, Beatriz Aibar Guzmán

\begin{tabular}{|c|c|c|}
\hline Empresa & Perspectiva do BSC & Fonte \\
\hline Nike & $\begin{array}{l}\text { Perspectiva de Processos Internos } \\
\text { Perspectiva Relacional/Clientes }\end{array}$ & Claver-Cortés et al. (2007) \\
\hline McDonald's & Perspectiva Relacional/Clientes & Claver-Cortés et al. (2007) \\
\hline FF Oy & Perspectiva de Processos Internos & Länsiluoto e Järvenpää (2007) \\
\hline Coop Adriatica & $\begin{array}{l}\text { Todas as perspectivas tradicionais } \\
\text { Perspectiva da Sociedade e do } \\
\text { Planeta }\end{array}$ & $\begin{array}{l}\text { Van der Woerd e Van den Brink } \\
(2004)\end{array}$ \\
\hline Granarolo & $\begin{array}{l}\text { Todas as perspectivas tradicionais } \\
\text { Perspectiva da Sociedade e do } \\
\text { Planeta }\end{array}$ & $\begin{array}{l}\text { Van der Woerd e Van den Brink } \\
(2004)\end{array}$ \\
\hline Shell Brasil & $\begin{array}{c}\text { Perspectiva do Desenvolvimento } \\
\text { Sustentável }\end{array}$ & Monteiro et al. (2003) \\
\hline Royal Dutch Shell & $\begin{array}{l}\text { Perspectiva do Desenvolvimento } \\
\text { Sustentável }\end{array}$ & Zingales e Hockerts (2003) \\
\hline Cetrel Brasil & Perspectiva de Processos Internos & Monteiro et al. (2003) \\
\hline Novo Nordisk & Todas as perspectivas tradicionais & Zingales e Hockerts (2003) \\
\hline Novartis & $\begin{array}{l}\text { Todas as perspectivas tradicionais } \\
\text { Desenvolvimento de um scorecard } \\
\text { para o departamento ambiental }\end{array}$ & $\begin{array}{l}\text { Zingales e Hockerts (2003) } \\
\text { Zingales et al. (2002a) }\end{array}$ \\
\hline SwissRe & Todas as perspectivas tradicionais & Zingales et al. (2002a) \\
\hline Nova Scotia Power & Perspectiva de Processos Internos & Zingales et al. (2002a) \\
\hline Lunds Energi & Perspectiva de Processos Internos & Zingales et al. (2002a) \\
\hline$A B B$ Sweden & Todas as perspectivas tradicionais & $\begin{array}{l}\text { Zingales et al. (2002a) } \\
\text { Olve et al. (1999) }\end{array}$ \\
\hline $\begin{array}{l}\text { Bristol Myers } \\
\text { Squibb }\end{array}$ & Todas as perspectivas tradicionais & Epstein e Wisner (2001) \\
\hline Mobil & Perspectiva de Processos Internos & Kaplan e Norton (2001) \\
\hline
\end{tabular}

Quadro 2: Exemplos de empresas que incluíram indicadores ambientais nos seus scorecards

\subsection{Modelos de BSC orientados ao desenvolvimento sustentável}

a) Sistema de Gestão e Avaliação do Desempenho Ambiental (SGADA)

Campos e Selig (2002) e Campos (2001), ao constatarem a existência de poucas referências na literatura sobre a utilização do BSC na gestão ambiental, apresentaram um Sistema de Gestão e Avaliação do Desempenho Ambiental (SGADA) ${ }^{11}$, no qual

\footnotetext{
${ }^{11} \mathrm{O}$ modelo foi desenvolvido e aplicado numa organização de grande porte do sector do entretenimento com o objectivo de inserir as questões estratégicas no contexto de gestão e desempenho ambiental.
} 
utilizam a metodologia do BSC para promover a integração entre as questões ambientais e as questões críticas e estratégicas da organização. Assim, para os autores este sistema apresenta como vantagens a integração de objectivos, metas e indicadores do desempenho ambiental à visão da organização, o desenvolvimento de conhecimentos e o aumento da compreensão tanto de questões ambientais como de outras questões estratégicas críticas da organização. Segundo os autores, existem três razões fundamentais que justificam a aplicação do BSC na gestão ambiental:

1. Relacionar o SGADA com a perspectiva de aprendizagem do BSC, considerando-a fundamental para a manutenção de um sistema de gestão ambiental (se não se investir na formação dos empregados, o sistema torna-se ineficaz, trazendo, em consequência, prejuízos para a organização e para o meio ambiente);

2. As relações de causa-efeito inerentes ao BSC permitem propagar efeitos positivos e evitar ou corrigir causas de efeitos negativos;

3. A visão top-down existente no BSC, ao permitir que as estratégias definidas pela gestão de topo cheguem aos níveis mais baixos da hierarquia organizacional, possibilita uma melhoria não só no processo de avaliação do desempenho ambiental, mas também na interacção deste desempenho com o desempenho global da organização, em concreto na retenção e conquista de clientes e, por conseguinte, nos resultados esperados.

Os referidos autores defendem a inclusão da perspectiva ambiental, além das perspectivas tradicionais apresentadas por Kaplan e Norton $(1996)^{12}$, na medida em que a questão ambiental é crítica para o êxito organizacional. Os factores críticos de êxito desta perspectiva são a procura da conformidade legal, o bom relacionamento com a comunidade, o correcto tratamento dos efluentes e resíduos gerados e o consumo de energia e água. Neste contexto, apresentaram um conjunto de indicadores

\footnotetext{
${ }^{12}$ No que respeita às perspectivas tradicionais, a denominação da perspectiva de processos internos foi substituída por perspectiva operativa, e a perspectiva de aprendizagem e crescimento por perspectiva das pessoas.
} 
do desempenho ambiental a ser incluídos nesta perspectiva, devendo estar alinhados com as estratégias, objectivos e metas organizacionais (com a óptica financeira, do cliente, dos processos internos e de aprendizagem e crescimento), por exemplo:

> Número de reclamações da comunidade, relacionadas com aspectos ambientais;

> Número de reclamações dos visitantes, relacionadas com aspectos ambientais;

$>$ Consumo de água por pessoa;

> Consumo de energia eléctrica por pessoa;

> Parâmetros ambientais exigidos pela legislação;

> Percentagem de resíduos inertes enviados para o ambiente;

$>$ Número de não conformidades legais registadas (por exemplo, multas).

b) O Sustainability Balanced Scorecard (SBSC)

O Sustainability Balanced Scorecard (SBSC) é um modelo cujo escopo é a detecção de objectivos de carácter social e ambiental de uma unidade de negócio ou de um departamento ou secção específicos, não se vinculando apenas a aspectos operacionais, mas também a estratégias de desenvolvimento e criação de riqueza. Neste sentido, enfatiza a abordagem do "resultado triplo" (económico-social-ambiental), destacando, além disso, o propósito económico, o propósito estratégico das empresas na sua relação com a sociedade e o meio ambiente. Segundo Hart (1997), as organizações que assumem estratégias sociais e ambientais explícitas estão mais propensas à adopção de um SBSC.

Para Hubbard (2009), Schaltegger e Wagner (2006) e Möller e Schaltegger (2005), o SBSC será benéfico na determinação do principal conteúdo do relatório de sustentabilidade. Além disso, a análise da eco-eficiência proporciona informação para o SBSC, funcionando como um vínculo entre o BSC e o sistema contabilístico ambiental. Para os autores, o BSC como um sistema aberto possibilita a consideração dos aspectos de sustentabilidade. No entanto, não distingue explicitamente nem equilibra os interesses de diferentes stakeholders e os aspectos de sustentabilidade e ecoeficiência. Assim, defendem o SBSC para ligar os pilares da sustentabilidade 
("resultado triplo"), realçando as relações de causa-efeito entre recursos, capacidades e actividades relacionadas com a mesma.

Nesta linha, o SBSC permite identificar os aspectos sociais e ambientais a que estão expostas as empresas, quais os aspectos que são estrategicamente relevantes para o êxito do negócio, e como são vinculados e integrados através de relações de causa-efeito representadas num mapa estratégico. O BSC, com a sua concepção multidimensional, está bem situado para fazer frente de maneira eficiente aos principais desafios das empresas na gestão da sustentabilidade. Daí que o SBSC combina medidas do desempenho e a gestão do desempenho em todas as dimensões de sustentabilidade.

Neste sentido, é uma abordagem orientada a melhorar a integração dos aspectos ambientais, sociais e económicos da medição e gestão da sustentabilidade das empresas. Os determinantes da sua utilização estão relacionados com o conjunto ou subconjunto de indicadores específicos definidos pelo sector industrial, o nível de interesse público, o rigor da legislação nacional, o tamanho da organização e a importância relativa dos stakeholders para a empresa (SCHALTEGGER; WAGNER, 2006; MÖLLER; SCHALTEGGER, 2005; FIGGE et al., 2002; SCHALTEGGER; FIGGE, 2000).

Figge et al. (2002) argumentam que o BSC permite identificar e gerir em simultâneo as melhorias sociais e ambientais e os objectivos financeiros do negócio. Assim, um SBSC coincide com o requerimento central do conceito de sustentabilidade, ou seja, com a permanente melhoria do desempenho do negócio em termos económicos, ecológicos e sociais. Os autores sugerem três passos na formulação de um SBSC: selecção da UEN, identificação dos aspectos sociais e ambientais, e determinação da importância estratégica dos mesmos através do processo top-down.

Neste sentido, Bieker (2002) e Bieker e Gminder (2001) referem que a definição de estratégias sociais e ambientais consistentes e adequadas é um pré-requisito do SBSC, assim como o envolvimento da gestão de topo, ajustando o negócio aos valores éticos e morais da organização. Os citados autores enfatizam que o BSC é utilizado 
frequentemente de forma instrumentalizada e redutora, ou seja, na prática observa-se o predomínio da perspectiva financeira, e por outro lado a recomendação de Kaplan e Norton (1996) de um máximo de 20 indicadores, o que pode levar a que os aspectos de sustentabilidade não sejam considerados com a mesma importância (não existe o "equilíbrio"), e à exclusão de outros stakeholders como a comunidade e a sociedade.

Assim, analisaram como o SBSC pode ser utilizado para traduzir as estratégias sustentáveis corporativas em acção e para integrar os aspectos sociais e ambientais no sistema de gestão central das organizações. O SBSC deve ser capaz de derivar eficientemente os objectivos e acções operacionais da política económica, social e ambiental da organização, clarificando a sustentabilidade corporativa ao forçar os gestores a definir estratégias sociais e ambientais e a identificar relações de causaefeito.

Para Bieker (2002), problemas de integração de aspectos qualitativos como os sociais e ambientais nos sistemas de controlo são especialmente relevantes uma vez que são difíceis de quantificar, além disso as organizações não possuem sistemas de controlo capazes de implementar e controlar aspectos ecológicos, sociais e económicos através de uma única ferramenta. O SBSC ajuda a detectar importantes objectivos estratégicos sociais e ambientais de uma organização e a ilustrar as relações entre os mesmos e o desempenho financeiro.

c) O modelo teórico de Gimeno et al. (2005)

Gimeno et al. (2005), motivados pela crescente importância para as organizações da gestão ambiental e na procura de uma ferramenta que permita melhorar a sua gestão, avaliaram a utilidade do BSC como ferramenta que permita uma adequada gestão da variável ambiental, no âmbito do desenvolvimento sustentável, criando valor tanto para os accionistas como para os diversos grupos de interesse. Neste sentido, desenvolveram um modelo teórico ${ }^{13}$, baseado no modelo de Kaplan e Norton (1996), orientado à consecução de objectivos financeiros para o alcance de um

\footnotetext{
${ }^{13}$ Aplicado ao grupo de empresas Repsol YPF.
} 
desenvolvimento sustentável, com o objectivo de criar valor global e melhorar o desempenho desde a tripla perspectiva (económica, ambiental e social), de proporcionar um modelo que facilite a tomada de decisões relativas à gestão ambiental a todos os níveis da estrutura empresarial, e de implicar e motivar toda a organização para um comportamento socialmente responsável.

Para os citados autores (2005: 7), o BSC "permite à organização controlar a sua gestão ambiental e interpretar os acontecimentos de modo que possa apresentar uma informação adequada, relevante, fiável e oportuna aos diferentes utilizadores da mesma". O modelo desenvolvido pelos autores propõe um conjunto de alterações respeito ao modelo tradicional, em concreto:

$>$ A redefinição da perspectiva financeira, passando a designar-se perspectiva de desenvolvimento sustentável para satisfazer os desafios da responsabilidade social da empresa, considerando além dos aspectos económicos, os aspectos ambientais e sociais. Propõem como objectivos estratégicos a incluir nesta perspectiva: incrementar e diversificar as receitas, reduzir custos a largo prazo e reduzir outros impactos negativos;

> Ampliam a perspectiva de clientes a uma perspectiva de grupos de interesse para considerar, além dos clientes, as relações que se estabelecem com os restantes grupos de interesse. Obter a satisfação dos diferentes grupos de interesse e a lealdade dos clientes, fomentar a adesão a princípios ecológicos e introduzir melhorias no ambiente são exemplos de objectivos estratégicos apontados;

> Incorporação dos critérios da responsabilidade social e gestão ambiental na perspectiva de processos internos, mediante a inovação, a redefinição de processos e a optimização de recursos. Como objectivos estratégicos sugerem: oferecer produtos e serviços ecológicos, implementar sistemas de gestão ambiental, obter transparência informativa e incorporar tecnologias limpas e ecológicas; 
> Enfatizam a importância da perspectiva de aprendizagem e crescimento na consecução dos objectivos da perspectiva de processos internos e, em consequência, na satisfação dos grupos de interesse que conduzirá a organização a alcançar um desenvolvimento sustentável. Consideram que os objectivos estratégicos a incluir nesta perspectiva respeitam à incorporação de tecnologia de informação, à gestão das competências do capital humano e à realização de alianças estratégicas.

d) O modelo teórico de Claver-Cortés et al. (2007)

Para Claver-Cortés et al. (2007), o BSC é uma ferramenta que permite fornecer a informação ambiental necessária para o desenvolvimento das actividades internas e para o conhecimento dos requisitos da sociedade, definindo claramente a visão e missão ambiental da organização. Na adaptação do BSC à perspectiva ambiental, os autores citados sugerem um modelo que se caracteriza por:

$>$ A perspectiva quantitativa em substituição da perspectiva financeira, para realçar os indicadores quantitativos (retorno do investimento, crescimento dos resultados, etc.);

$>$ A perspectiva de processos internos para informar sobre os recursos e capacidades disponíveis [antecipação às necessidades dos consumidores "verdes" e às actividades dos concorrentes; capacidade para inovar através da introdução de novas tecnologias (processos de produção "limpos", equipamento menos contaminante, produtos ecológicos) e de novas estratégias (auditoria ambiental, certificação); avaliação do sistema de gestão ambiental e de gestão da informação; reputação e reconhecimento no âmbito ecológico];

> A perspectiva relacional em substituição da perspectiva de clientes, uma vez que as organizações deverão valorizar além das relações com os clientes, as relações com outros agentes directa e indirectamente implicados no desenvolvimento das actividades da organização (nível de satisfação dos clientes respeito à actuação ambiental da organização; intensificação das 
relações com os fornecedores; respeito ao desenvolvimento de produtos "verdes"; alianças estratégicas no estabelecimento de programas e sistemas ambientais; estimular o diálogo entre os stakeholders para a recolha e divulgação de informação);

> A perspectiva de formação e aprendizagem para incluir os investimentos nas capacidades individuais e dos sistemas e procedimentos organizacionais (formação nas temáticas ambientais e melhoria contínua; responsabilidade ambiental dos empregados e aumento da concorrência nesta matéria; alinhamento dos objectivos individuais com a estratégia ambiental e corporativa).

\section{e) O BSC e a Global Reporting Initiative (GRI)}

Gilli (2007) propõe a integração dos indicadores de sustentabilidade da GRI no BSC para obter um feedback adequado em matéria de responsabilidade social (Quadro 3). Assim, será importante medir o impacto da actividade das empresas a partir de um BSC, proporcionando uma visão mais integral da gestão empresarial incluindo indicadores de responsabilidade social. Neste sentido, Gilli (2007, p. 1031) refere que o propósito do BSC de revelar os indutores para a criação de valor desde uma perspectiva de largo prazo, é consistente com o objectivo do relatório de sustentabilidade "que pretende a medição, divulgação e prestação de contas relativamente ao objectivo de desenvolvimento sustentável, entendendo como tal a satisfação das necessidades presentes sem colocar em perigo a capacidade de satisfaze-las no futuro".

$\mathrm{Na}$ GRI, a explicitação da estratégia e da visão da Direcção constitui o primeiro elemento do relatório de sustentabilidade. De modo similar, os objectivos e indicadores do BSC derivam da visão e da estratégia da organização. Assim, o único requisito adicional será a incluso das questões de responsabilidade social na visão e estratégia da empresa. 
O Balanced Scorecard e a Gestão Ambiental: Um Estudo no Sector Público e Privado Português

Patricia Rodrigues Quesado, Lúcia Lima Rodrigues, Beatriz Aibar Guzmán

\begin{tabular}{|c|c|}
\hline Perspectivas do BSC & Indicadores do relatório de sustentabilidade da GRI \\
\hline Perspectiva Financeira & $\begin{array}{c}\text { Total de receitas; } \\
\text { Salários e contribuições; } \\
\text { Compras e contratos com fornecedores; } \\
\text { Investimentos em infra-estruturas e serviços; } \\
\text { Controlo do impacto ambiental; } \\
\text { Programas de acção social. }\end{array}$ \\
\hline Perspectiva do Cliente & $\begin{array}{c}\text { Número de acordos de investimento e } \\
\text { aprovisionamento com cláusulas específicas em } \\
\text { matéria ambiental e de direitos humanos (por exemplo, } \\
\text { trabalho de menores, não discriminação, cuidado } \\
\text { ambiental); } \\
\text { Número de incumprimentos de códigos e regulações } \\
\text { em matéria de saúde e segurança do cliente ou de } \\
\text { publicidade; } \\
\text { Número de reclamações por fugas à privacidade de } \\
\text { dados pessoais. }\end{array}$ \\
\hline Perspectiva de Processos Internos & $\begin{array}{c}\text { Tipos e quantidades de materiais utilizados; } \\
\text { Consumo de energia repartido por tipo de fonte; } \\
\text { Quantidade de emissões, descargas e resíduos; } \\
\text { Percentagem de materiais recuperados; } \\
\text { Redução do impacto ambiental; } \\
\text { Controlo da salubridade e segurança dos produtos e } \\
\text { serviços. }\end{array}$ \\
\hline $\begin{array}{l}\text { Perspectiva de Aprendizagem e } \\
\text { Crescimento }\end{array}$ & $\begin{array}{c}\text { Repartição de equipas por tipo de emprego, relação } \\
\text { contratual e localização, sexo, faixa etária, pertença a } \\
\text { minorias; } \\
\text { Relações entre o salário de homens e mulheres; } \\
\text { Horas médias de formação, distribuídas por categorias; } \\
\text { Vigência da livre associação; } \\
\text { Seguimento do desenvolvimento de carreiras; } \\
\text { Taxas de absentismo, doenças profissionais e } \\
\text { acidentes de trabalho; } \\
\text { Horas de formação em prevenção da saúde e } \\
\text { acidentes; } \\
\text { Percentagem de empregados formados em temas } \\
\text { éticos e em práticas anti-corrupção; } \\
\text { Participação dos empregados em projectos sociais; } \\
\text { Número de causas relacionadas com práticas } \\
\text { monopolistas ou o número de sanções e multas por } \\
\text { incumprimento de leis e regulamentos. }\end{array}$ \\
\hline
\end{tabular}

Quadro 3: A inclusão de indicadores do relatório de sustentabilidade da GRI nas perspectivas do BSC Fonte: Elaboração própria, a partir de Gilli, 2007, p. 1032-1033.

Para López e Llena (2006), as crescentes pressões que sofrem as empresas por parte do ambiente social levaram à extensão da implementação da RSC no âmbito da 
gestão interna e da comunicação com o exterior, implicando o desenvolvimento de técnicas e ferramentas de gestão que facilitem a análise das questões sociais e ambientais, mediante o estabelecimento de linhas estratégicas a seguir, como de objectivos operacionais e relatórios a apresentar à gestão e a terceiros. Neste sentido, propõem a incorporação da RSC no desenvolvimento do $\mathrm{BSC}^{14}$ como uma linha estratégica a gerir e analisar pela entidade, desenvolvendo uma proposta de possível inclusão do conjunto de indicadores propostos na GRI na gestão estratégica através do BSC $^{15}$. Para os citados autores, em cada uma das perspectivas do BSC é possível incorporar distintos objectivos, tanto de carácter interno como externo, relacionados com o âmbito social ou ambiental.

Concordamos com os referidos autores na consideração de que o BSC será útil se com a gestão ambiental se pretender a inovação e o desenvolvimento sustentável. Assim, as propostas realizadas pela GRI ajudam na fase de selecção e eleição de indicadores a incluir no scorecard, que integre a RSC tanto como linha estratégica (com a vantagem de considerar de forma equilibrada e causal distintos objectivos que têm uma estreita relação com a RSC), como uma quinta perspectiva (derivada da flexibilidade do BSC) ou simplesmente através da definição de alguns objectivos de especial relevância a considerar em qualquer das perspectivas tradicionalmente utilizadas, mas sempre dentro das perspectivas de natureza interna.

f) O BSC e a gestão ambiental em Portugal

A literatura estudou escassamente a inter-relação entre o BSC e a gestão ambiental portuguesa. Nos poucos trabalhos em que se aborda esta questão, a abordagem baseia-se em estudos de casos concretos.

\footnotetext{
${ }^{14}$ Para Vergino et al. (2007), as organizações devem incluir nas perspectivas do BSC a RSC uma vez que são abordagens que partilham características comuns: tratar os clientes com ética, transparência e confiança, melhorar a qualidade de vida da sociedade, capacidade para atrair e manter especialistas, compromisso e implicação dos colaboradores, utilização racional de recursos e promoção da imagem positiva da empresa frente aos seus stakeholders.

${ }^{15}$ Ting (2005) sugere a utilização do BSC baseado na abordagem da GRI em cada uma das áreas de RSC (produtos/serviços; ambiente natural; empregados e comunidade).
} 
Assim, Dias-Sardinha et al. (2007) investigaram a implementação do SBSC ${ }^{16}$ em três grandes empresas portuguesas ${ }^{17}$ interessadas pelas questões de sustentabilidade mas também uma estratégia corporativa explícita respeito às mesmas e sem uma experiência prévia com o BSC. Concluíram que os principais benefícios do SBSC centram-se na capacidade para relatar a sustentabilidade no formato da Global Reporting Initiative (GRI) e a inclusão das questões de sustentabilidade na estratégia de negócio de toda a organização. As principais dificuldades apontadas foram a falta de interesse por parte de alguns membros da organização, a qualificação do pessoal e a falta de uma estrutura de sustentabilidade bem definida. Os inquiridos assinalaram ainda a necessidade de uma perspectiva separada para medir o desempenho financeiro do negócio.

Dias-Sardinha et al. (2002) analisaram o tipo de indicadores utilizados e a utilizar na avaliação do desempenho ambiental por parte de organizações industriais e de serviços portuguesas. Concluíram que as organizações portuguesas estão interessadas na avaliação do desempenho ambiental, tentando alterar os seus objectivos estratégicos no sentido de incluir a eco-eficiência. Para os autores, o BSC tradicional deve mudar no sentido de indicar o nível de desempenho social e ambiental que a organização espera alcançar. Propõem um BSC em cascada desde o nível corporativo até ao nível das UEN e dos departamentos individuais com as perspectivas de ecoeficiência ou de sustentabilidade, stakeholders, processos e aprendizagem. Concluíram que as pequenas e médias empresas não praticam uma avaliação formal do desempenho ambiental, e que as grandes empresas possuem processos de avaliação do desempenho mais sistemáticos e parecem mais ambiciosas no que concerne às actividades sociais e ambientais.

Dias-Sardinha e Reijnders (2005) classificam as organizações portuguesas em três categorias segundo o seu comportamento e desempenho social e ambiental: controlo da poluição, prevenção da poluição, e eco-eficiência, utilizando distintos

\footnotetext{
${ }^{16}$ Com as perspectivas de criação de valor triple bottom line, stakeholders internos e externos, processos/produtos e aprendizagem e inovação.

${ }^{17}$ EDP, Lusotur e Sonae Imobiliaria.
} 
scorecards em distintas categorias. Para os autores, o BSC é útil para identificar as forças e debilidades das relações entre variáveis de avaliação do desempenho. Referem que todas as perspectivas do BSC devem incluir indicadores relativos à sustentabilidade, sugerindo a inclusão de indicadores propostos pela GRI nas perspectivas:

$>$ Criação de valor triple bottom line ${ }^{18}$ : quais os aspectos sociais e ambientais chave e suas consequências financeiras;

> Stakeholders ${ }^{19}$ : quais os aspectos sociais e ambientais a medir para satisfazer os stakeholders internos e externos;

> Processos internos: que processos internos e externos a organização possui para medir os aspectos sociais, ambientais e económicos;

$>$ Aprendizagem ${ }^{20}$ : quais as capacidades de inovação e aprendizagem para levar em conta e medir os aspectos sociais, ambientais e económicos.

\section{METODOLOGIA}

Como meio básico para a recolha dos dados optamos pela realização de um inquérito através do envio de um questionário a uma amostra de organizações públicas e privadas que operam em Portugal. Em particular, a população objecto de estudo está formada por grandes empresas, pequenas e médias empresas (PME's), câmaras municipais, empresas municipais (EM), empresas intermunicipais (EIM) e hospitais públicos pertencentes ao Sistema Nacional de Saúde (SNS).

No caso das grandes empresas utilizamos a base de dados das 500 maiores e melhores empresas portuguesas classificadas em função do seu volume de vendas publicado na edição especial da "Revista Exame" referente ao ano 2007 (Exame, 2008). No que respeita às PME's, decidimos seleccionar unicamente as pertencentes ao sector industrial que foram classificadas como excelentes nos dos últimos anos em que se

\footnotetext{
${ }^{18}$ Equivalente à perspectiva financeira de Kaplan e Norton (1996).

${ }^{19}$ Equivalente à perspectiva de clientes de Kaplan e Norton (1996).

${ }^{20}$ Equivalente à perspectiva de aprendizagem e crescimento de Kaplan e Norton (1996).
} 
realizou tal classificação (2000 e 2001). No que concerne às câmaras municipais e EM/EIM, decidimos seleccionar todas as câmaras municipais e EM/EIM portuguesas. Finalmente, seleccionamos todos aqueles hospitais pertencentes ao SNS classificados até finais de Março de 2009 como Entidades Públicas Empresariais (EPE) e Sector Público Administrativo (SPA).

Face ao exposto, a população objecto de estudo está composta por 1.140 organizações: as 388 maiores empresas portuguesas, 161 PME's excelência-indústria, 308 câmaras municipais, 222 EM/EIM e 61 instituições hospitalares (39 hospitais EPE e 22 hospitais SPA).

Os questionários foram testados durante o mês de Março de 2009 por elementos pertencentes à população a investigar assim como por académicos conhecedores do tema em estudo e com ampla experiência no desenho e realização de investigações através de inquéritos.

A fase de recolha da informação teve lugar entre Abril de 2009 e Março de 2010 e os dados foram tratados estatisticamente com recurso ao programa SPSS (Statistical Package for the Social Sciences - versão 17).

Dos 1.140 questionários enviados obtivemos 357 respostas, o que corresponde a $31,3 \%$ do total da população. Estes questionários distribuem-se da seguinte maneira entre as distintas organizações inquiridas: 107 grandes empresas $(27,6 \%), 48$ PME's (29,8\%), 100 câmaras municipais (32,5\%), 87 EM/EIM (39,2\%) e 15 hospitais (24,6\%).

\section{ESTUDO EMPÍRICO}

\subsection{Hipótese de investigação}

Russo (2009) e Russo e Martins (2005) referem que existe uma maior utilização do BSC em empresas certificadas, na medida em que a estas empresas normalmente se thes exigem comportamentos de gestão mais racionais, o desenvolvimento de iniciativas para melhorar a qualidade e maior formalização das áreas funcionais e dos seus procedimentos. Além disso, os referidos autores assinalam que existem vários 
aspectos comuns entre o BSC e os sistemas de certificação, em concreto, referem-se ao desenvolvimento formal (explícito) da estratégia, a gestão dos processos internos e das relações com os clientes.

Neste contexto, pensamos que seria interessante comprovar até que ponto a certificação ambiental da organização está associada à maior (ou menor) adopção do BSC. Em consequência, formulamos a seguinte hipótese relativa à existência de uma relação entre o BSC e os sistemas de certificação:

H1: A utilização do BSC é maior nas organizações portuguesas certificadas em termos ambientais.

\subsection{Resultados}

\subsubsection{Implementação do BSC}

Com o propósito de conhecer em que medida está ou não generalizada a utilização do BSC nas organizações públicas e privadas portuguesas, questionamos os inquiridos que conhecem o BSC sobre o grau de utilização do mesmo ${ }^{21}$. A este respeito, em termos gerais, a aplicação do BSC é mais reduzida nas organizações pertencentes ao sector público do que nas do sector privado. Não obstante, este resultado deve-se exclusivamente às grandes empresas. Efectivamente, como se observa nas Tabelas 1 e 2, a maior percentagem de organizações que afirmam que utilizam o BSC pertencem ao grupo de grandes empresas $(38,6 \%)$.

Os resultados obtidos revelam que o nível de implementação do BSC nas PME's, câmaras municipais, EM/EIM e hospitais portugueses é bastante reduzido. No entanto, quando comparamos os nossos resultados com os obtidos noutros estudos prévios realizados em Portugal (QUESADO; RODRIGUES, 2009; SANTOS, 2006; QUESADO, 2005; RUSSO; MARTINS, 2005; SILVA, 2003; SOUSA, 2001) constatamos que houve um incremento na utilização do BSC nos últimos anos. Além disso, um importante número de organizações indicou que pretende implementar o BSC no futuro e,

\footnotetext{
${ }^{21}$ Duas PME’s, uma EM/EIM e três câmaras municipais não responderam a esta questão.
} 
inclusive, algumas organizações referiram que já estavam a dar os primeiros passos no seu processo de implementação.

Tabela 1: Utilização do BSC nas organizações privadas

\begin{tabular}{|c|c|c|c|c|}
\hline Utilização & Grandes & $\%$ & PME's & $\%$ \\
\hline Não utilizam nem pretendem utilizar & 44 & 50 & 20 & 74,1 \\
\hline Utilizam actualmente & 34 & 38,6 & 1 & 3,7 \\
\hline Já utilizaram o BSC mas abandonaram & 2 & 2,3 & 1 & 3,7 \\
\hline Esperam implementar no futuro & 8 & 9,1 & 5 & 18,5 \\
\hline Total & $\mathbf{8 8}$ & $\mathbf{1 0 0}$ & $\mathbf{2 7}$ & $\mathbf{1 0 0}$ \\
\hline
\end{tabular}

Tabela 2: Utilização do BSC nas organizações públicas

\begin{tabular}{|c|c|c|c|c|c|c|}
\hline Utilização & $\begin{array}{c}\text { Câmaras } \\
\text { Municipais }\end{array}$ & $\%$ & EM/EIM & $\%$ & Hospitais & $\%$ \\
\hline $\begin{array}{c}\text { Não utilizam nem pretendem } \\
\text { utilizar }\end{array}$ & 47 & 74,6 & 33 & 71,7 & 6 & 46,2 \\
\hline Utilizam actualmente & 3 & 4,8 & 2 & 4,3 & 1 & 7,7 \\
\hline Esperam implementar no futuro & 13 & 20,6 & 11 & 23,9 & 6 & 46,2 \\
\hline Total & $\mathbf{6 3}$ & $\mathbf{1 0 0}$ & $\mathbf{4 6}$ & $\mathbf{1 0 0}$ & $\mathbf{1 3}$ & $\mathbf{1 0 0}$ \\
\hline
\end{tabular}

\subsubsection{Sistemas de certificação ambiental e elaboração de relatórios de sustentabilidade}

Nas Tabelas seguintes apresentamos a informação relativa à existência nas organizações objecto de análise de certificação de sistemas de gestão ambiental e de relatórios de sustentabilidade.

No âmbito das organizações pertencentes ao sector privado (Tabela 3) é possível constatar que cinquenta e quatro grandes empresas já possuem ou encontram-se em vias de implementar algum tipo de certificação ambiental, frente às doze PME's que possuem ou estão em vias de obter a referida certificação ${ }^{22}$. A quase totalidade das organizações com certificação ambiental tem a Certificação ISO 14001, em três empresas coexistem as certificações ISO 14001 e EMAS y em duas empresas as certificações ISO 14001 e OHSAS 18001.

\footnotetext{
${ }^{22} \mathrm{O}$ facto de que mais de metade das PME's não tenham investido em sistemas de certificação deste tipo pode ser um sinal de que os seus mercados alvo não o exigem (Russo e Martins, 2005).
} 
O Balanced Scorecard e a Gestão Ambiental: Um Estudo no Sector Público e Privado Português

Patricia Rodrigues Quesado, Lúcia Lima Rodrigues, Beatriz Aibar Guzmán

Tabela 3: Certificação ambiental das grandes empresas e PME's

\begin{tabular}{|c|c|c|c|c|}
\hline $\begin{array}{c}\text { Certificação } \\
\text { ambiental }\end{array}$ & $\begin{array}{c}\text { Grandes } \\
\text { Empresas }\end{array}$ & $\%$ & PME's & $\%$ \\
\hline Sim & 41 & 38,7 & 6 & 12,5 \\
\hline Não & 52 & 49,1 & 36 & 75 \\
\hline Em curso & 13 & 12,3 & 6 & 12,5 \\
\hline Total & $\mathbf{1 0 6}$ & $\mathbf{1 0 0}$ & $\mathbf{4 8}$ & $\mathbf{1 0 0}$ \\
\hline
\end{tabular}

Também procuramos obter informação respeito à elaboração de relatórios de sustentabilidade e/ou ambientais por parte das organizações privadas da amostra. Como se pode observar na Tabela 4 , mais de metade das grandes empresas $(53,8 \%)$ e uma grande percentagem de PME's $(70,2 \%)$ não elabora tais relatórios.

Tabela 4: Elaboração de relatório de sustentabilidade e/ou ambientais nas grandes empresas e PME's

\begin{tabular}{|c|c|c|c|c|}
\hline & Grandes Empresas & $\%$ & PME's & $\%$ \\
\hline Sim & 49 & 46,2 & 14 & 29,8 \\
\hline Não & 57 & 53,8 & 33 & 70,2 \\
\hline Total & $\mathbf{1 0 6}$ & $\mathbf{1 0 0}$ & $\mathbf{4 7}$ & $\mathbf{1 0 0}$ \\
\hline
\end{tabular}

Em relação à obtenção de certificação ambiental e à elaboração de relatórios de sustentabilidade e/ou ambientais por parte das EM/EIM e das Câmaras Municipais da amostra, as Tabelas 5 e $6^{23}$ indicam que apenas seis empresas estão certificadas em termos ambientais (ISO 14001) e doze empresas elaboram relatórios de sustentabilidade e/ou ambientais. No que se refere às Câmaras Municipais, a quase totalidade $(92,9 \%)$ não possui certificação ambiental e aquelas que indicaram estar certificadas obtiveram certificação com base nas normas ISO 14001 e OHSAS 18001. Por outro lado, apenas um número reduzido de Câmaras Municipais elaboram relatórios de sustentabilidade e/ou ambientais (10,1\%).

\footnotetext{
${ }^{23}$ Uma empresa não respondeu a esta questão.
} 
O Balanced Scorecard e a Gestão Ambiental: Um Estudo no Sector Público e Privado Português

Patricia Rodrigues Quesado, Lúcia Lima Rodrigues, Beatriz Aibar Guzmán

Tabela 5: Certificação ambiental em EM/EIM e Câmaras Municipais

\begin{tabular}{|c|c|c|c|c|}
\hline & EM/EIM & $\%$ & Câmaras Municipais & $\%$ \\
\hline Sim & 6 & 7 & 5 & 5,1 \\
\hline Não & 74 & 86 & 92 & 92,9 \\
\hline Em curso & 6 & 7 & 2 & 2 \\
\hline Total & $\mathbf{8 6}$ & $\mathbf{1 0 0}$ & $\mathbf{9 9}$ & $\mathbf{1 0 0}$ \\
\hline
\end{tabular}

Tabela 6: Elaboração de relatórios de sustentabilidade e/ou ambientais nas EM/EIM e nas Câmaras Municipais

\begin{tabular}{|c|c|c|c|c|}
\hline & EM/EIM & $\%$ & Câmaras Municipais & $\%$ \\
\hline Sim & 12 & 14 & 10 & 10,1 \\
\hline Não & 74 & 86 & 89 & 89,9 \\
\hline Total & $\mathbf{8 6}$ & $\mathbf{1 0 0}$ & $\mathbf{9 9}$ & $\mathbf{1 0 0}$ \\
\hline
\end{tabular}

Finalmente, no que respeita à certificação ambiental e à elaboração de relatórios de sustentabilidade e/ou ambientais nos hospitais públicos (Tabelas 7 e 8), à semelhança do que ocorreu no caso das outras organizações inquiridas, a quase totalidade dos hospitais EPE da amostra $(81,8 \%)$ não possui certificação ambiental, embora seja importante o número de hospitais EPE que elaboram relatórios de sustentabilidade e/ou ambientais (45,5\%). Por outro lado, a totalidade dos hospitais SPA não possui certificação ambiental nem elaboram relatórios de sustentabilidade e/ou ambientais.

Tabela 7: Certificação ambiental nos hospitais

\begin{tabular}{|c|c|c|c|c|c|c|}
\hline Certificação ambiental & EPE & $\%$ & SPA & $\%$ & Total & $\%$ \\
\hline Sim & 1 & 9,1 & 0 & 0 & 1 & 6,7 \\
\hline Não & 9 & 81,8 & 4 & 100 & 13 & 86,6 \\
\hline Em curso & 1 & 9,1 & 0 & 0 & 1 & 6,7 \\
\hline Total & $\mathbf{1 1}$ & $\mathbf{1 0 0}$ & $\mathbf{4}$ & $\mathbf{1 0 0}$ & $\mathbf{1 5}$ & $\mathbf{1 0 0}$ \\
\hline
\end{tabular}

Tabela 8: Elaboração de relatórios de sustentabilidade e/ou ambientais nos hospitais

\begin{tabular}{|c|c|c|c|c|c|c|}
\hline & EPE & $\%$ & SPA & $\%$ & Total & $\%$ \\
\hline Sim & 5 & 45,5 & 0 & 0 & 5 & 33,3 \\
\hline Não & 6 & 54,5 & 4 & 100 & 10 & 66,7 \\
\hline Total & $\mathbf{1 1}$ & $\mathbf{1 0 0}$ & $\mathbf{4}$ & $\mathbf{1 0 0}$ & $\mathbf{1 5}$ & $\mathbf{1 0 0}$ \\
\hline
\end{tabular}




\subsubsection{Os indicadores sociais e ambientais}

No âmbito do estudo realizado foi possível observar que mais de metade das organizações objecto de estudo ${ }^{24}$ (56,8\% organizações privadas e $54,2 \%$ organizações públicas) ${ }^{25}$ incluem nos seus scorecards indicadores sociais e ambientais. No âmbito público, dez organizações indicaram que tais indicadores integraram-se nas quatro perspectivas tradicionais, enquanto uma organização pretende integrá-los na perspectiva de processos internos.

Por outra parte, nas vinte e quatro organizações privadas que responderam a esta questão as respostas dividem-se. Assim, nove organizações integraram os indicadores sociais e ambientais apenas em alguma ou algumas das perspectivas tradicionais sugeridas por Kaplan e Norton $(1996)^{26}$, em oito organizações foi criado um scorecard específico para a gestão ambiental ${ }^{27}$, seis organizações incluíram os citados indicadores nas quatro perspectivas tradicionais e apenas numa organização se acrescentou uma perspectiva adicional para tal efeito (se bem que esta organização não mencionou a denominação que deu a esta perspectiva).

No que se refere aos impactos da integração dos indicadores sociais e ambientais no BSC, seis organizações privadas (16,7\%) e cinco organizações públicas indicaram que tal integração proporcionou uma melhoria da gestão ambiental e da sustentabilidade $(41,7 \%)$.

\subsubsection{Análise bivariada}

Para testar a hipótese definida relativa à associação entre a utilização do BSC e a existência de sistemas de certificação ambiental, realizamos uma análise bivariada mediante a utilização do teste de independência Qui-quadrado.

\footnotetext{
${ }^{24}$ Tendo em conta o número reduzido de organizações da amostra que utilizam o BSC, apresentaremos todos os resultados agregados por sectores: privado (grandes empresas e PME's) e público (câmaras municipais, EM/EIM e hospitais).

2544 organizações privadas e 24 públicas responderam a esta questão.

${ }^{26}$ Uma organização assinalou a perspectiva de aprendizagem e crescimento, quatro indicaram a perspectiva de processos internos ou equivalente (infra-estruturas) e duas organizações mencionaram a perspectiva de processos internos e a perspectiva de aprendizagem e crescimento.

27 Além disso, uma destas organizações comentou que, na sua opinião, as perspectivas tradicionais do BSC não são adequadas para responder às organizações preocupadas com questões ambientais e de desenvolvimento sustentável.
} 
Os resultados desta análise corroboram a hipótese definida neste estudo ( $p$ value $=0,017$ ), embora a relação entre as variáveis não seja muito elevada ( $V$ de Cramer $=0,186)$. Assim, as empresas certificadas em termos ambientais utilizam em maior medida o BSC que as empresas não certificadas.

Tabela 9: Certificação ambiental vs implementação do BSC

\begin{tabular}{|c|c|c|c|c|}
\hline \multicolumn{2}{|c|}{ Utilização do BSC } & \multicolumn{3}{c|}{ Certificação ambiental } \\
\cline { 3 - 5 } & Sim & Não & Em curso \\
\hline \multirow{2}{*}{ Utiliza o pretende utilizar } & Casos & 25 & 50 & 8 \\
\cline { 2 - 5 } & \% certificação & 49 & 29,6 & 50 \\
\hline \multirow{2}{*}{ No utiliza } & Casos & 26 & 119 & 8 \\
\cline { 2 - 5 } & \% certificação & 51 & 70,4 & 50 \\
\hline
\end{tabular}

$\left(p\right.$-value $=0,017 ; x^{2}=8,145 ; V$ de Cramer $\left.=0,186\right)$

\section{CONSIDERAÇÕES FINAIS}

Nos últimos anos incrementou-se a importância da sustentabilidade como um factor de êxito organizacional e a sua divulgação nos relatórios de gestão de organizações públicas e privadas (LÄNSILUOTO; JÄRVENPÄÄ, 2007). Zingales e Hockerts (2003) argumentam que o êxito do BSC depende da capacidade das organizações para integrarem indicadores não financeiros na gestão estratégica como é o caso da natureza intangível de indicadores do desempenho social e ambiental.

Através do presente estudo foi possível comprovar que existem vários modelos e distintas possibilidades de integração da informação estratégica ambiental num BSC, variando de organização para organização. Assim, os aspectos sociais e ambientais podem estar representados, na forma de medidas estratégicas de resultado ou drivers do desempenho, nas perspectivas clássicas do BSC corporativo, numa perspectiva adicional (para aumentar a sua visibilidade ou porque não é fácil a sua inclusão nas perspectivas tradicionais) ou num scorecard específico para uma UEN (departamento ambiental, por exemplo). 
Em consonância com os estudos de Quesado e Rodrigues (2009), Santos (2006), Quesado (2005), Russo e Martins (2005), Silva (2003) e Sousa (2001), os resultados indicam uma baixa utilização do BSC em Portugal (76,5\% das organizações privadas e $62,7 \%$ das públicas conhecem tal ferramenta, mas apenas $41,7 \%$ das organizações privadas e $29,5 \%$ das públicas utilizam ou esperam utilizar o BSC). Não obstante, devemos ressaltar que o nosso estudo apresenta taxas de conhecimento e utilização do BSC superiores às registadas noutros estudos prévios realizados em Portugal, o que indica que a popularidade da referida ferramenta de gestão aumentou nos últimos anos.

Verificamos também que são sobretudo as grandes empresas que já possuem ou encontram-se em vias de implementar algum tipo de certificação ambiental, sendo a certificação ambiental nas PME's, EM/EIM, Câmaras Municipais e Hospitais pertencentes ao SNS bastante reduzida. Além disso, foi possível observar que tanto nas organizações privadas como nas organizações públicas a elaboração de relatórios de sustentabilidade e/ou ambientais é uma prática pouco utilizada.

Quanto à inclusão de indicadores sociais e ambientais nos scorecards das organizações, observamos que a maioria das organizações quer pertençam ao sector privado quer pertençam ao sector público incluem nos seus scorecards tais indicadores, dividindo-se as respostas quanto à forma de integração (à semelhança do que foi possível observar no âmbito da revisão da literatura efectuada).

Finalmente, ao nível da comprovação da hipótese de investigação, obtivemos evidência empírica respeito à relação entre a implementação do BSC e a existência de sistemas de certificação ambiental, ou seja, as empresas certificadas em termos ambientais utilizam mais o BSC do que as não certificadas.

\section{REFERÊNCIAS}

ASOCIACIÓN ESPAÑOLA DE CONTABILIDAD Y ADMINISTRACIÓN DE EMPRESAS, AECA. (1996). Contabilidad de Gestión Medioambiental. Madrid, AECA, febrero. 
BANEGAS OCHOVO, R.; NEVADA PEÑA, D.; TEJADA PONCE, Á. (2000). El Cuadro de Mando como Instrumento de Control en la Gestión Social: Recursos Humanos y Medio Ambiente. Revista Española de Financiación y Contabilidad, enero/marzo, 103: 107-147.

BASTIDAS BERMÚDEZ, E.; RIPOLL FELIU, V. (2003). Una Aproximación a las Implicaciones del Cuadro de Mando Integral en las Organizaciones del Sector Público. Revista Compendium, diciembre, 11: 23-41.

BEJA, R. (2003). Balanced Scorecard e Desenvolvimento Sustentável. Revisores e Empresas, Outubro/Dezembro, 23: 7-11.

BIEKER, T. (2002). Managing Corporate Sustainability with the Balanced Scorecard: Developing a Balanced Scorecard for Integrity Management. Oikos PhD Summer Academy, Foundation for Economy and Ecology, University of St. Gallen.

BIEKER, T. e GMINDER, C. (2001). Towards a Sustainability Balanced Scorecard. Oikos PhD Summer Academy, Foundation for Economy and Ecology, University of St. Gallen.

CAMPOS, L. e SELIG, P. (2002). SGADA - Sistema de Gestão e Avaliação do Desempenho Ambiental: A Aplicação de um Modelo de SGA que Utiliza o Balanced Scorecard (BSC). Revista Read, Novembro/Dezembro, 8(6): 1-23.

CAMPOS, L. (2001). SGPA - Sistema de Gestão e Performance Ambiental: Uma Proposta de Implementação de um Sistema de Gestão Ambiental Utilizando o Balanced Scorecard. Dissertação de Mestrado. Universidade Federal de Santa Catarina, Brasil.

CHALMETA, R. e PALOMERO, S. (2011). Methodological Proposal for Business Sustainability Management by Means of the Balanced Scorecard. The Journal of the Operational Research Society, 62(7): 1344-1356.

CLAVER-CORTÉS, E.; LÓPEZ-GAMERO, M.; MOLINA-AZORÍN, J.; ZARAGOZASÁEZ, P. (2007). Intellectual and Environmental Capital. Journal of Intellectual Capital, 8(1): 171-182.

DIAS-SARDINHA, I.; REIJNDERS, L.; ANTUNES, P. (2007). Developing Sustainability Balanced Scorecards for Environmental Services: A Study of Three Large Portuguese Companies. Environmental Quality Management, Summer, 16(4): 13-34.

DIAS-SARDINHA, I. e REIJNDERS, L. (2005). Evaluating Environmental and Social Performance of Large Portuguese Companies: A Balanced Scorecard Approach. Business Strategy and the Environment, March/April, 14(2): 73-91. 
DIAS-SARDINHA, I. e REIJNDERS, L. (2001). Environmental Performance Evaluation and Sustainability Performance Evaluation of Organizations: An Evolutionary Framework. Eco-Management and Auditing, June, 8(2): 71-79.

DIAS-SARDINHA, I.; REIJNDERS, L.; ANTUNES, P. (2002). From Environmental Performance Evaluation to Eco-Efficiency and Sustainability Balanced Scorecards. Environmental Quality Management, Winter, 12(2): 51-64.

EPSTEIN, M. e WISNER, P. (2001). Using a Balanced Scorecard to Implement Sustainability. Environmental Quality Management, Winter, 11(2): 1-10.

EXAME. (2008). 500 Maiores \& Melhores. Revista Exame, Edição Especial 2008, Outubro.

FIGGE, F.; HAHN, T.; SCHALTEGGER, S.; WAGNER, M. (2002). The Sustainability Balanced Scorecard - Linking Sustainability Management to Business Strategy. Business Strategy and the Environment, September/October, 11(5): 269-284.

GATES, S.; GERMAIN, C. (2010). Integrating Sustainability Measures into Strategic Performance Measurement Systems: An Empirical Study. Management Accounting Quarterly, Spring, 11(3): 1-6.

GILLI, J. (2007). Indicadores de Responsabilidad Social: Inclusión en el Cuadro de Mando Integral. In: X Congresso Internacional de Custos, 13-15 Junho, 2007, Lyon, pp. 1021-1034.

GIMENO ZUERA, J.; MONEVA ABADÍA, J. M.; LAMEDA MONTERO, I. (2005). La Variable Medioambiental en el Cuadro de Mando Integral. In: I Conferência LusoEspanhola em Gestão e Contabilidade Ambiental, 5-6 Maio, 2005, Leiria.

HART, S. (1997). Beyond Greening: Strategies for a Sustainable World. Harvard Business Review, January/February, 75(1): 66-76.

HSU, Y.; LIU, C. (2010). Environmental Performance Evaluation and Strategy Management Using Balanced Scorecard. Environmental Monitoring and Assessment, November, 170(1/4): 599-607.

HUBBARD, G. (2009). Measuring Organizational Performance: Beyond the Triple Bottom Line. Business Strategy and the Environment, March, 18(3): 177-191.

JOHNSON, S. (1998). Identification and Selection of Environmental Performance Indicators: Application of the Balanced Scorecard Approach. Corporate Environmental Strategy, Summer, 5(4): 34-41. 
KAPLAN, R.; NORTON, D. (2008). Mastering the Management System. Harvard Business Review, 86(1) 62-77.

KAPLAN, R.; NORTON, D. (2007a). Using the Balanced Scorecard as a Strategic Management System. Harvard Business Review, 85(7/8): 150-161.

KAPLAN, R.; NORTON, D. (2007b). Alignment: Cómo Alinear la Organización a la Estrategia a través del Balanced Scorecard. Barcelona, Gestión2000.

KAPLAN, R.; NORTON, D. (2006). How to Implement a New Strategy without Disrupting your Organization. Harvard Business Review, 84 (3): 100-109.

KAPLAN, R.; NORTON, D. (2004). Mapas Estratégicos - Convirtiendo los Activos Intangibles en Resultados Tangibles. Barcelona, Gestión2000.

KAPLAN, R.; NORTON, D. (2001). Cómo Utilizar El Cuadro de Mando Integral para Implantar y Gestionar la Estrategia. Barcelona, Gestión2000.

KAPLAN, R.; NORTON, D. (2000). El Cuadro de Mando Integral. Barcelona, Gestión2000.

KAPLAN, R.; NORTON, D. (1996). Translating Strategy into Action - The Balanced Scorecard. Massachusetts, Harvard Business School Press.

KAPLAN, R.; NORTON, D. (1992). The Balanced Scorecard - Measures that Drive Performance. Harvard Business Review. 70(1): 71-79.

LAMEDA MONTERO, I. e GIMENO ZUERA, J. (2009). Cuadro de Mando para la Gestión Ambiental. In: XV Congresso da Associação Espanhola de Contabilidade e Administração de Empresas (AECA), 23 a 25 de Setembro, 2009, Valladolid.

LÄNSILUOTO, A. e JÄRVENPÄÄ, M. (2010). Greening the Balanced Scorecard. Business Horizons, July/August, 53: 385-395.

LÄNSILUOTO, A. e JÄRVENPÄÄ, M. (2008). Environmental and Performance Management Forces: Integrating "Greenness" into Balanced Scorecard. Qualitative Research in Accounting and Management, 5(3): 184-206.

LÄNSILUOTO, A. e JÄRVENPÄÄ, M. (2007). Sustainability and Performance Management - A Case of Implementation of Sustainable Balanced Scorecard in a Food Processing Company. In: $30^{\text {th }}$ Annual Congress of the European Accounting Association, 25-27 April, 2007, Lisboa. 
LEÓN SORIANO, R.; MUÑOZ TORRES, M.; CHALMETA ROSALEÑ, R. (2010). Methodology for Sustainability Strategic Planning and Management. Industrial Management \& Data Systems, 110(2): 249-268.

LÓPEZ GORDO, M. (2006). Medio Ambiente y Cuadro de Mando Integral. In: XVI Jornadas Luso-Espanholas de Gestão Científica, 1-3 Fevereiro, 2006, Évora.

LÓPEZ VIÑEGLA, A.; LLENA MACARULLA, F. (2006). La Incorporación de la Responsabilidad Social Corporativa en la Gestión Estratégica a través del Balanced Scorecard. Revista AECA, enero/abril, 74: 46-51.

MASIDE SANFIZ, J.; AIBAR GUZMÁN, B. (1999). Distintas Posibilidades de Integración de la Información Estratégica Medioambiental en un Cuadro de Mando Integral. Estudio de Dos Casos de "SIGMA" en Base a su Estructura de Propiedad. In: VI Congresso Internacional de Custos, 15-17 Setembro, 1999, Braga.

MÖLLER, A.; SCHALTEGGER, S. (2005). The Sustainability Balanced Scorecard as a Framework for Eco-Efficiency Analysis. Journal of Industrial Ecology, Fall, 9(4): 73-83.

MONTEIRO, P.; CASTRO, A.; PROCHNIK, V. (2003). A Mensuração do Desempenho Ambiental no Balanced Scorecard e o Caso da Shell. In: VII Encontro Nacional sobre Gestão Empresarial e Meio Ambiente, Outubro, 2003, Brasil.

MORO PRIETO, M.; FERNÁNDEZ RODRÍGUEZ, E. (2003). El Cuadro de Mando Integral al Servicio de la Nueva Gestión Empresarial. In: VIII Jornada de Trabajo sobre Contabilidad de Costes y de Gestión, ASEPUC, noviembre, 2003, pp. 171-186.

OLVE, N.; ROY, J.; WETTER, M. (1999). Performance Drivers: A Practical Guide to Using the Balanced Scorecard. New York, John Wiley \& Sons.

QUESADO, P. (2005). O Contributo do Balanced Scorecard para a Gestão Estratégica de Custos: Uma Análise Empírica às Grandes Empresas Portuguesas. Dissertação de Mestrado, Universidade do Minho, Braga.

QUESADO, P.; RODRIGUES, L. (2009). Factores Determinantes na Implementação do Balanced Scorecard em Portugal. Revista Universo Contábil, 5(4): 94-115.

ROCHA, J.; NEVES, R.; SELIG, P. (2001). Balanced Scorecard na Gestão Ambiental. In: VII Congreso Interamericano sobre el Medio Ambiente, 5-7 diciembre, 2001, Chile.

RUSSO, J. 2009. Balanced Scorecard para PME e Pequenas e Médias Instituições. Lisboa, Lidel Edições Técnicas. (2 ed.). 
RUSSO, J.; MARTINS, A. (2005). A Aplicabilidade do Balanced Scorecard nas PME: O Caso da Indústria Transformadora de Matérias Plásticas do Centro Litoral de Portugal. Jornal de Contabilidade, 344: 401-418.

SANTOS, R. (2006). Balanced Scorecard em Portugal: Visão, Estratégia e Entusiasmo. Lisboa, Gestão Plus Edições.

SCHALTEGGER, S.; FIGGE, F. (2000). Environmental Shareholder Value. Economic Success with Corporate Environmental Management. Eco-Management and Auditing, 7(1): 29-42.

SCHALTEGGER, S.; WAGNER, M. (2006). Integrative Management of Sustainability Performance, Measurement and Reporting. International Journal of Accounting, Auditing and Performance Evaluation, 3(1): 1-19.

SILVA, C. (2003). A Utilização e o Conhecimento do Balanced Scorecard em Portugal: Uma Análise Empírica ao Mapa da Estratégia das Empresas Portuguesas. (Dissertação de Mestrado). Universidade do Minho, Braga.

SOUSA, M. (2001). A Aplicação do Balanced Scorecard em Portugal. (Dissertação de Mestrado). Universidade do Porto, Porto.

TING, H. 2005. Does Implementation of "Balanced" Management Systems Lead to Better Corporate Social Responsibility? In: $3^{\text {rd }}$ Conference on Performance Measurement and Management Control, 22-23 September, 2005, Nice.

TORRES AGUDELO, F. (2001). Cuadro de Mando Integral Ambiental para PYME's: Experiencia en Colombia, In: VII Congreso Interamericano sobre el Medio Ambiente, 5-7 Diciembre, 2001, Chile.

VAN DER WOERD, F.; VAN DEN BRINK, T. (2004). Feasibility of a Responsive Business Scorecard - A Pilot Study. Journal of Business Ethics, December, 55(2): 173186.

VERGINO, E.; FERREIRA, F.; SILVA, D. (2007). A Influência da Responsabilidade Social Corporativa na Aplicação do Balanced Scorecard. In: Congresso Internacional de Administração, 17-21 Setembro, 2007, Brasil.

YONGVANICH, K. e GUTHRIE, J. (2006). An Extended Performance Reporting Framework for Social and Environmental Accounting. Business Strategy and the Environmental, September/October, 15(5): 309-321. 
ZINGALES, F. e HOCKERTS, K. (2003). Balanced Scorecard and Sustainability: Examples from Literature and Practice. Centre for the Management of Environmental Resources, Working Papers Series, 2003/30/CMER.

ZINGALES, F.; O'ROURKE, A.; HOCKERTS, K. (2002a). Balanced Scorecard and Sustainability State of the Art Review. Centre for the Management of Environmental Resources, Working Papers Series, 2002/65/CMER.

ZINGALES, F.; O'ROURKE, A.; ORSSATTO, R. (2002b). Environment and SocioRelated Balanced Scorecard: Exploration of Critical Issues. Centre for the Management of Environmental Resources, Working Papers Series, 2002/47/CMER.

Data de Submissão: 13/02/2012

Data de Aceite: 10/11/2012 